Article

\title{
Sustainable Collaboration to Support Vulnerable Youth: Mental Health Support Teams in Upper Secondary School
}

\author{
Cecilie Anvik* and Ragnhild Holmen Waldahl \\ Nordland Research Institute, 8049 Bodø, Norway, E-Mails: cecilie.h.anvik@nord.no (C.A.), rhw@nforsk.no (R.H.W.) \\ * Corresponding author
}

Submitted: 5 April 2018 | Accepted: 6 August 2018 | Published: 28 September 2018

\begin{abstract}
Schools play a central role in preventing mental health problems from affecting the development and educational opportunities of youth. While school health and social pedagogical support services have expanded in many countries, they are still not considered sufficient in meeting the needs of vulnerable youth. We find particular challenges in the development of sustainable collaboration to support the target group. In this article, we present and analyze empirical data from ongoing trailing research on an interprofessional team focusing on the health and psychosocial conditions of students in various upper secondary schools in Norway. In the article, we discuss what conditions need to be in place for inter-professional collaboration to succeed in the efforts to support students at risk of dropping out of upper secondary school. The article is theoretically influenced by boundary literature and analyzes challenges and opportunities in boundary crossing between different professions and service areas. In the article, we argue for the need to spend time on establishing a reflecting understanding of which qualities the various actors possess and what they should contribute with to create a collaboration that constitutes more than the coordination of what already exists, thereby creating intersecting practices; so-called third spaces.
\end{abstract}

\section{Keywords}

collaboration; drop out; interprofessional team; mental health; Norway; school; student; support; vulnerable youth

\section{Issue}

This article is part of the issue "Vulnerable and Disadvantaged Groups: On the Margins of the Welfare State?", edited by Inger Lise Skog Hansen and Tone Fløtten (Fafo Institute for Labour and Social Research, Norway).

(C) 2018 by the authors; licensee Cogitatio (Lisbon, Portugal). This article is licensed under a Creative Commons Attribution 4.0 International License (CC BY).

\section{Introduction}

The Nordic welfare states are characterized as being service intensive, with comprehensive public initiatives that are meant to ensure the welfare of the general population and, more specifically, vulnerable groups. This makes these welfare states both robust and complicated at the same time. In such complex societies, knowledge and expertise is becoming increasingly specialized (Edwards, 2011; Hjörne \& Säljö, 2014) and divided into different political and bureaucratic sectors of responsibility. At the same time, these societies experience that some of the challenges they face are too complex for individual actors to solve on their own (Lagreid \& Rykkja, 2015).
Such kinds of problems are referred to as wicked problems and described as being complex and difficult to define and resolve (Bjørgo, Sandvin, \& Hutchinson, 2015; Morris \& Miller-Stevens, 2015; Rittel \& Webber, 1973). A wicked problem may be viewed as a problem with many "owners", whereby each "owner" has his/her own understanding of the problem, while no single actor's solution is adequate in resolving the issue. When tasks and service areas become as complex as a wicked problem, the need for collaboration arises (Lagreid \& Rykkja, 2015), also in the form of multidisciplinary team work (Fay, Borrill, Amir, Haward, \& West, 2006).

In the Nordic countries, as in the rest of the OECD countries, there are increasing concerns for the growing 
number of young people who are neither employed nor attending school while simultaneously struggling with mental health issues (OECD, 2012, 2016). Early intervention is highlighted as being important to help this group of children and youth (OECD, 2012). Schools are a central arena in succeeding with early intervention. However, despite the fact that school health and socialpedagogical support services have expanded in many countries, this is not considered sufficient in meeting the complexity of the needs of children and youth. Research on multidisciplinary teams find that placing professionals from different sectors together in teams, such as public health teams, does not necessarily guarantee new and improved services (Fay et al., 2006; Hjörne \& Säljö, 2014). Insufficient cooperation between stakeholders and services, within and outside of school, constitute particular challenges (Anvik \& Waldahl, 2017; OECD, 2012; Stephan, Weist, Kataoka, Adelsheim, \& Mills., 2007).

Many studies, including our own, point out the need to place greater focus on interaction as the solution to the complexity of such problems; nonetheless, little attention has yet been given to how this may take place. This article seeks to draw attention to new ways of interprofessional collaboration to expand on the understanding of this. In the article, we ask what conditions need to be in place for inter-professional collaboration to succeed in the efforts to support students at risk of dropping out of upper secondary school. In an ongoing study, "Complete", we conduct trailing research on an intervention in various upper secondary schools in Norway. ${ }^{1}$ The intervention is a so-called Mental Health Support Team (MHST), an interprofessional team focusing on health and psychosocial conditions. The intervention represents one link in strengthening the collaboration to support students who struggle within the framework of the upper secondary school system. Through systematic, goal-oriented and early efforts, the purpose of the intervention is to prevent youth from dropping out of school and ending up on the outskirts of the labor market. The establishment of MHSTs may be viewed as an attempt to coordinate and collaborate across both sectoral and professional boundaries. It is theoretically framed by some central concepts taken from boundary literature, wherein the focus is directed at crossing boundaries between different fields or social realms (Akkerman \& Bakker, 2011). The literature describes, in various ways, the dynamics of and conditions for different actors to cross a variety of social realms.

\section{More on Student Services in Upper Secondary School}

According to the Norwegian Education Act (Norwegian Ministry of Education, 1998), schools should make "ac- tive and systematic efforts to promote a good psychosocial environment, where individual pupils can experience security and social belonging" (§9A-3). To safeguard the requirements of this law resources are set aside-both in and outside of schools-to address the students' social, emotional and academic challenges, in addition to supporting them in questions of future careers. The resources included in student services vary somewhat from school to school, but the functions that are constant throughout are, first and foremost: counselors, pedagogical psychological services and nurses. Furthermore, there is a follow-up service in all provinces that is responsible for supporting youth under the age of 21 who have the right to training but are not employed or under training (§3-6). Whether the follow-up service is located in or outside the schools varies. The intervention, MHST, is organized as its own team under the student services of each school, with particular focus on youth who are on the brink of dropping out of upper secondary training. The teams are particularly meant to help deal with the students' social and emotional challenges. The teams consist of counselors, nurses, and follow-up services. All the follow-up services that are part of the MHST are located in the school. The teams are supposed to work closely with individual students as well as being systematically directed at the school and its surroundings. The teams have a particular focus on systematic follow-up work in addition to being available to and working closely with the youth. MHST is built on resources that already exist in or around the school.

\section{Theoretical Framework}

While MHSTs are a trial to test interaction between professions and services, we theoretically approach the topic by referencing boundary literature. As a means of perspective, boundary literature places focus on what happens during boundary crossings between situated practices (Akkerman \& Bakker, 2011; Engeström, Engeström, \& Kärkkäinen, 1995; Star, 2010; Star \& Griesemer, 1989; Suchman, 1994; Wenger, 2000). A boundary makes up a space, a marker between different areas that both divides and connects them. As an analytical term, "boundary" clarifies the state of belonging to one and several sites at the same time. As a point of departure, boundaries are not viewed as barriers. Interaction across different sites (boundary crossing) and lasting collaboration between actors from different sites (boundary practices) also encompass the potential for dialogue between diverse perspectives and understandings; and, therefore, the establishment of spaces for transfer, change and development (Akkerman \& Bakker, 2011; Suchman, 1994).

Boundary crossing creates a discontinuity in established practices and actions, which makes it possible to

\footnotetext{
${ }^{1}$ Complete is an ongoing school-based research project in upper secondary schools of four counties in Norway, led by the University of Bergen, with Nordland Research Institute as a partner. The trial period is August 2016-June 2019. The project consists of two interventions, where the Mental Health Support Team (MHST) is one of them, aimed at following up specific students at risk of dropping out. Complete is one of four national research projects aimed at reducing drop out, financed by the Norwegian Ministry of Education and Research.
} 
identify and negotiate around both challenges and solutions that may be useful in new settings (Akkerman \& Bakker, 2011; Star \& Griesemer, 1989). As a means of perspective, we find boundary crossing particularly beneficial in analyzing collaboration across professions and sectors because it:

Allows a more fine-grained understanding of the required new relationships and cultural perceptions, as it is specifically targeted at analyzing challenges and learning opportunities of situations in which diverse stakeholders (e.g., different disciplines or institutions) need to collaborate. (Akkerman \& Bruining, 2016, p. 248)

In an extensive literature review, Akkerman and Bakker (2011) identify four mechanisms that may occur in situations of boundary crossing: identification, coordination, reflection and transformation. Identification is a process that occurs in situations where previous boundaries between practices become uncertain or destabilized. Identification deals with redefining the diverse practices by asking questions about the core operations of the various practices and becoming aware of and directing focus towards how the different intersecting practices exist in relation to one another. "This questioning leads to renewed insight into what the diverse practices concern" (Akkerman \& Bakker, 2011, p. 142) and how they may legitimately coexist. The next central element in boundary crossing interaction is coordination. Coordination makes it possible for "diverse practices to cooperate efficiently in distributed work" (Akkerman \& Bakker, 2011, p. 143). Coordination may be viewed as a communicative distribution of work and duties, in which the dialogue is nonetheless "established only as far as is necessary to maintain the flow of work" (Akkerman \& Bruining, 2016, p. 245). This may happen through routinization, among other things, whereby coordination becomes automated. Through reflection, the actors may become aware of and make explicit distinctions between their own and others' practices, thereby learning about and understanding their own and others' practices in new ways (Akkerman \& Bakker, 2011). As an alternative to coordination, Akkerman and Bakker bring up transformation to characterize what happens when the actors are confronted with their own practices and continually strive to initiate joint works. With transformation, the practice is changed and a "new, in-between practice" (Akkerman \& Bakker, 2011 , p. 146) is created. When different practices intersect, and elements from diverse contexts are negotiated and combined in new ways, what is referred to in literature as "third spaces...that allow negotiation of meaning" are created (Akkerman \& Bakker, 2011, p. 135; Engeström et al., 1995). This must be embedded in the existing practices to achieve "real consequences" (Akkerman \& Bakker, 2011, p. 148).

\section{Method}

The authors of this article are part of a research team that conducts trailing research (2016-2019) on the implementation of MHSTs. The trailing research may be divided into two parallel tracks: 1 ) observation of the intervention's implementation process, and 2) school interviews towards the end of the first year of the intervention. As part of point 1, the researchers participated in the introduction of the intervention; joined the intervention team for information rounds in all of the six schools prior to initiation of the service (early spring 2016); participated in a new visit to all of the schools to follow the training each MHST received from the intervention team (late spring 2016), in which the researchers' role was to observe how the service respond to the schools' and student services' needs for interaction to support students struggling to finish upper secondary schooling; and observed two experience exchange meetings (fall 2016, spring 2017), in which the intervention team gathered all MHSTs from the six schools for a joint full-day meeting. The purpose of the meeting was to give the MHSTs the opportunity to share experiences and discuss challenges and opportunities associated with the implementation of the intervention. Additionally, the intervention and research teams have had monthly meetings in which the research team was updated on the status of the implementation (fall 2016-spring 2017). Furthermore, as part of point 2, the researchers have carried out fieldwork (spring 2017) in the six schools (2-4 days per school). One of the purposes of the fieldwork was to discern the status of the MHST intervention as far into the trial period as possible. In the overall project we conducted 119 interviews with administrators, lead teachers, students and those professional actors who make up the MHST (counselors, nurses and provincial follow-up coordinators), 83 transcripts provided relevant data for answering our research question. The findings presented here are based on data from the observations of the MHST implementation and interviews with members of the MHSTs, teachers and administrators. We analyze boundary crossing on an interpersonal level (Akkerman \& Bruining, 2016), with focus on relations and interaction between specific actors from different practices. For the analytical work we have employed what Tjora (2012) calls a stepwisedeductive-inductive method, whereby we work stepwise with the analyses, both inductively and deductively. In so doing, we have continually moved between raw data and concepts in the development of the analytical categories. The theory and concepts from boundary literature have been of significant help during thematic text analysis (Berg \& Lune, 2012). In the analytical work, we have found inspiration in the four mechanisms of boundary crossing described in the theory section, defined by Akkerman and Bakker (2011) as identification, coordination, reflection and transformation. 


\section{Findings and Discussion}

Among the various actors in and around the schools, we find an overall interest in and willingness to get started with MHSTs. Administrators, teachers and student service staff alike felt that a growing number of students were struggling with personal issues, particularly related to mental health, and that the support students receive comes too late and is not well coordinated. The informants further express a reasonable degree of support for the intervention and its understanding of problems (e.g., many students who struggle while falling through the cracks, lack of routines and systematic collaboration), means (e.g., MHST teams, collaboration and routines) and objectives (e.g., to get involved more quickly, prevent drop out among students and more effectively use resources now, while working together rather than parallel). During data collection, we have not registered that staff directly opposed or worked against the implementation of the team. According to Akkerman and Bakker (2011) a shared problem space is a central prerequisite for boundary practices.

At the same time, we found some confusion and ambiguity at several of the schools as to what the MHST was, and what roles and tasks they had, both in relation to student services in general, and for the pedagogical staff. Upon initiation of the MHST one counselor asked, "How do we define the MHST so that it's distinguished from school nursing services, student services, etc.?" At several of the schools, a lot of time was used to clarify and distinguish the roles and responsibilities of the MHST versus the other student services and the MHST versus the teachers. Although the introduction of the service has brought with it some "clutter" and initial difficulties, this has more to do with role clarification at the schools than with the general attitude towards the intervention.

While MHSTs challenge the boundaries between the team and the rest of the school, they also represent new roles for team members. This is most clearly expressed in relation to the position of follow-up services on the team and at the school. This particularly applies to schools where provincial follow-up services have not previously been involved. At such schools, follow-up services have only gotten involved with the school when a student is already on the brink of dropping out. Although the intention of MHSTs was that follow-up services would be an equal partner in the team and a natural part of the school, several of the follow-up service representatives nonetheless feel they are behind the scenes: "I wish I were a more visible part of the work at the school but, instead, I feel that a lot of what I do today is, in a way, a bit too connected to behind-the-scenes work".

Although the will exists to make the teams work, we see that they have had challenges in identifying both the boundaries between MHSTs and the rest of the school and the roles within the team, particularly that of the follow-up services. We find that such challenges primarily had to do with a lack of identification of the boundaries between the diverse professional fields and their responsibilities and duties from the start. The subject of what the new roles and tasks of the follow-up services meant for the collaboration between actors was not discussed within the teams or at the schools. It seems as though the consensus that MHSTs represented something positive has led to a lack of awareness and identification of one's own and others' academic and professional boundaries. During the identification process, the boundaries between practices are "encountered and reconstructed, without necessarily overcoming discontinuities" (Akkerman \& Bakker, 2011, p. 12). Star and Griesemer (1989) point out that cooperation across boundaries does not require consensus. In fact, a lack of consensus may be advantageous as the actors when confronted by the boundaries between professional fields are forced to become more aware of their own position, such that they negotiate to a greater degree for the intersection of practices.

The focus at the schools and in the MHSTs has rather been to establish a structure for the follow-up work to prevent "things slipping through the cracks", as one counselor expressed it. To a considerable degree, this has meant coordinating and distributing work duties and coming up with joint routines. One administrator said that, before the initiation of MHSTs, "we had some routines, but didn't follow up on them". This is a common feature at several of the schools, that they had routines before the start of MHSTs, but that they were not well known or followed. For these actors, the implementation of MHSTs represented an opportunity to put things into a system. One MHST counselor said: "We've perhaps gotten things more in order, worked with the students. We've gotten some set routines". When asked specifically what the MHST does, one counselor responded:

A bit more formalization of, "Ok, who does what now and who can help now?", and clarifying things. When we get a referral to the MHST, we now work on a bit more formalization of the tasks ahead: what are the student's tasks, what will the lead teacher do, what will the counselor do? In other words, we arrange agreements.

A common feature of the schools and the MHST teams has been to spend a lot of time the first year on developing routines. Although many of the schools have succeeded with this, some schools continually experience setbacks in that routines are not followed. It can thus seem that, even though the teams and schools acknowledge that routines contribute to "maintaining the flow of work" (Akkerman \& Bakker, 2011, p. 143), they have not yet reached the point where the work flows "smoothly without costs" (Akkerman \& Bakker, 2011, p. 144). This may be due to the fact that the teams have not adequately achieved a dialogue with the organization. There is a tendency for the teams to be introverted in their focus and this may have diminished the dialogue with the organization. 
According to Star (2010) coordination means that diverse practices collaborate more effectively in distributed work. These are features we find at the schools, where the teams are characterized by members who still work somewhat parallel to one another on their own case/duties. At the same time, both team members and other school staff at some other schools point out that the establishment of MHSTs has led to new working methods in which professionals such as counselors, nurses and follow-up coordinators work more closely in sync together. Common to all of these is the common idea, though expressed differently, that they are working together in new ways, which makes them see the youth and their own and others' practices in a new and other light. One administrator underscored that, with the initiation of MHSTs, interprofessional work is lifted up and has more transparency: "I believe the work with MHSTs makes the practice of counseling services less private, you eventually establish a professional environment and some mutual ground". Another administrator welcomed new professions in school, bringing in other perspectives: "There is another way of doing things, another way of receiving students, another way of acting with students, in various situations. So, I see that this is something for the future".

In addition to seeing the value of interprofessional work, one MHST member claimed that:

We have become clearer about the competence we have. Many have competence, [and through the MHST collaboration] we get to better use the entirety of it. Has the team messed up or cleaned up? Some roles give of themselves, but we have had to discuss how we are going to do it.

The above is an example of how certain actors reflect on their own and others' practices.

Questions may be asked about whether the challenges that arose underway during implementation of the MHSTs and the daily interactive practice could have been avoided or addressed much earlier on, and if the implications of boundary crossing had been acknowledged from the start. Akkerman and Bakker describe boundary crossing as the "enactment of multivoiceness" (2011, p. 142). For the individual interactive actor, this involves an awareness of and reflection on what their role was before they entered into the collaboration, as well as what they will contribute to the team to create a joint basis for cooperation. Reflection, according to Akkerman and Bakker (2011), means a "process that emphasizes the role of boundary crossing in coming to realize and explicate differences between practices and thus to learn something new about their own and others' practices" (2011, p. 144). Reflection not only leads to consensus but also to the formulation of a distinctive perspective, "making explicit one's understanding and knowledge of a particular issue" (Akkerman \& Bakker, 2011, p. 145).

Through reflection and shift in perspective, actors may identify, define and learn something new about dif- ferences between their own and others' practices. "Taking another perspective is a way to begin to see things in a different light" (2011, p. 145). Difficulties in the interaction in and around the MHSTs have occurred when they have stumbled onto and felt the boundaries between the different practices. As one follow-up coordinator described the first year in the team: "It became a difficult time for me, I simply didn't feel welcome. I felt she would come with her babble...just because we have different ways of doing our job". Feeling the boundaries lead to frustration and insecurity, through which team members risk getting stuck in their own perspective rather than managing to view things from another's.

Transformation takes collaboration one step further. While coordination may be viewed as distribution and division of duties and roles (Akkerman \& Bakker, 2011), such as the various MHSTs have achieved to varying degrees, transformation adds something more. Transformation directs the focus towards the idea that boundary crossing is precisely what happens in intersecting practices. In boundary crossing, one moves away from one's own standpoint, gaining access to the other actors' perspectives and understandings. Wenger calls this "a chance to explore the edge of your competence, learn something entirely new, revisit your little truths, and perhaps, expand your horizon" (2000, p. 233). For boundary crossing to occur with MHSTs, the individual followup coordinators, school nurses and counselors must possess a boundary crossing competence, "the ability to manage and integrate multiple, divergent discourses and practices across social boundaries" (Akkerman \& Bakker, 2011, p. 140). Based on what each one brings to the interaction, they must be armed with the ability to transform it together and create something new, called the "third space" (Akkerman \& Bakker, 2011, p. 140). As one administrator said, "establish a professional environment and some mutual ground". According to Akkerman and Bakker:

Transformation leads to profound changes in practices, potentially even the creation of a new, inbetween practice: The studies that describe transformation processes consistently start with describing the confrontation with some lack or problem that forces the intersecting worlds to seriously reconsider their current practices and the interrelations. If such a confrontation is not occurring, transformation cannot be expected. (2011, p. 146)

During the interviews after almost one year's operation of MHST, few show examples of transformation. There are attempts. For example, when a team member describes the inception of the team as a transition from previously "sending students" to each other to now stopping up and finding out what specific help the student needs. At the same time, based on the interviews, it is difficult to identify concrete examples of transformation that have occurred in the MHSTs. 


\section{Conclusion}

The study of MHSTs shows that it is demanding to achieve good interprofessional collaboration. This is despite the fact that the teams are made up of existing actors who already know each other and are located in or around the school. The consensus, in both the teams and schools, about the benefit and need for closer interprofessional collaboration to support youth who are neither attending school nor employed while simultaneously struggling with mental issues, characterized the establishment of the teams. However, absence of confrontation from the start led to the teams spending a lot of time the first year on identifying what the roles within the team should be and how the teams should relate to the rest of the school. In particular, it seems that the teams' introverted focus has been somewhat at the expense of a dialogue with the rest of the school. The consequence has been that the teams have also spent a lot of time achieving good coordination.

Particularly in the teams that have achieved identification and coordination, we see attempts at reflection on their own and others' practices. After one year's trial of MHST, however, we see few concrete examples of transformation. Thus, time seems to be an important factor in achieving good interprofessional collaboration. Less than one year is likely too little time to see concrete examples of transformation.

At the same time, we would like to specify that identification and coordination are likely not enough to solve wicked problems. If a solution to a wicked problem with many owners is to be found there is a need for collaboration in which the actors/owners reflect on their own practices and, together, transform existing welfare services into new intersecting practices. Another aspect of identification and coordination is that these are not sufficient in helping to tear the different actors away from their own bureaucratic contexts. This can be explained with an increasing focus on goals and result management within the different sectors of responsibility. This helps to create so-called vertical loyalties, which make horizontal interactions between sectors and service providers difficult (Vike, 2013).

In a previous study, we have shown examples of so-called welfare navigators; i.e., individual actors who possess the ability and competence to cross their own boundaries in the work of comprehensive follow-up of youth with complex problems (Anvik \& Waldahl, 2017). What characterizes these individuals is that they are local service providers who operate beyond and across their sectors or mandates and create room for horizontal interactions. These individuals often have skills, competence and experience that transcend their sectors, along with good knowledge of the responsibilities of other sectors and work methods. They are able to see and handle youth's complex needs and work closely around the youth. These welfare navigators help in closing the gap between youth's complicated challenges and needs in ev- eryday life and the fragmented sector responsibilities of the welfare state (Anvik \& Waldahl, 2017). MHSTs may be seen as an attempt to better systematize this and create intersecting practices around youth who struggle to complete school.

Based on our own and others' research in the field, we believe there is a need for increased interprofessional work and efforts to support students, both in primary and secondary school, who struggle in their daily routines at school (Anvik \& Waldahl, 2017; Olsen, Gustavsen, \& Anvik, 2017). The need for more collaboration is raised in various contexts within welfare policy, administration and research alike. In this article, we have argued for the significance of having a greater focus on the work of providing comprehensive services to youth with complex needs. We have pointed to the necessity of taking time to establish a mutual understanding of what the work should constitute and the various roles the individual actors should contribute with, in addition to a focus on the idea that this collaboration should be more than a coordinating unit that distributes tasks among themselves but rather creates inter-sectional, multi-professional teams that become something more than the sum of the individual actors' sector mandates-so-called third spaces. Therefore, in our opinion, boundary literature's concepts and perspectives are well suited to broadening the understanding of processes in which different practices and perceptions transcend boundaries and meet to try and create comprehensive efforts to address wicked problems. This will benefit schools when it comes to the need for increased interprofessional work and school efforts to support children and youth who have complex challenges, also in primary schools. Such a focus, we believe, may also constitute a model for more sustainable collaboration within the public service sector as well as between the public and volunteer/private sectors.

\section{Acknowledgments}

A sincerely appreciation goes to all the participants effort in planning and carrying out the interventions, and complying with the interviews. The authors also want to thank the rest of the team in the research project. This research has been funded by the Ministry of Education and Integration in Norway.

\section{Conflict of Interests}

The authors declare no conflict of interests.

\section{References}

Akkerman, S. F., \& Bakker, A. (2011). Boundary crossing and boundary objects. Review of Educational Research, 81(2), 132-169.

Akkerman, S. F., \& Bruining, T. (2016). Multilevel boundary crossing in a professional development school partnership. Journal of the Learning Sciences, 25(2), 
240-284.

Anvik, C. H., \& Waldahl, R. H. (2017). Excluded youth in Iceland, the Faroe Islands and Norway. Nordic Welfare Research, 2(1), 17-29.

Berg, B. L., \& Lune, H. (2012). Qualitative research methods for the social sciences. New Jersey: Pearson Education Inc.

Bjørgo, F., Sandvin, J. T., \& Hutchinson, G. S. (2015). Gjenstridige problemer og samarbeidsdrevet innovasjon [Wicked problems and collaborative innovation]. In O. J. Andersen, L. Gårseth-Nesbakk, \& T. Bondas (Eds.), Innovasjon i offentlig tjenesteyting [Innovation in public services]. Bergen: Fagbokforlaget.

Edwards, A. (2011). Building common knowledge at the boundaries between professional practices: Relational agency and relational expertise in systems of distributed expertise. International Journal of Educational Research, 50(1), 33-39.

Engeström, Y., Engeström, R., \& Kärkkäinen, M. (1995). Polycontextuality and boundary crossing in expert cognition: Learning and problem solving in complex work activities. Learning and Instruction, 5(4), 319-336.

Fay, D., Borrill, C., Amir, Z., Haward, R., \& West, M. A. (2006). Getting the most out of multidisciplinary teams: A multiple-sample study of team innovation in health care. Journal of Occupational and Organizational Psychology, 79, 553-567.

Hjörne, E., \& Säljö, R. (2014). Analysing and preventing school failure: Exploring the role of multiprofessionality in pupil health team meetings. International Journal of Educational Research, 63, 5-14.

Lagreid, P., \& Rykkja, L. H. (2015). Organizing for "wicked problems". Analyzing coordination arrangements in two policy areas: Internal security and the welfare administration. International Journal of Public Sector Management, 28(6), 475-493. doi:10.1108/IJPSM01-2015-0009

Morris, J. C., \& Miller-Stevens, K. (2015). Advancing collaboration theory: Models, typologies, and evidence (Vol. 13): New York: Routledge.
Norwegian Ministry of Education. (1998). The Norwegian Education Act. Oslo: Norwegian Ministry of Education.

OECD. (2012). Sick on the Job? Myths and realities about mental health and work. Paris: OECD Publishing.

OECD. (2016). Society at a Glance 2016. OECD social indicators. A spotlight on youth. Paris: OECD Publishing. doi:10.1787/9789264261488-en

Olsen, T., Gustavsen, A., \& Anvik, C. H. (2017). Vær i skole: Lavterskeltilbud med spesialistkompetanse [Stay in school: Low-thresholds services with specialist competence]. No 1001. Bod $\varnothing$ : Nordland Research Institute.

Rittel, H. W., \& Webber, M. M. (1973). Dilemmas in a general theory of planning. Policy Sciences, 4(2), 155-169.

Star, S. L. (2010). This is not a boundary object: Reflections on the origin of a concept. Science, Technology, \& Human Values, 35(5), 601-617.

Star, S. L., \& Griesemer, J. R. (1989). Institutional ecology, 'translations' and boundary objects: Amateurs and professionals in Berkeley's Museum of Vertebrate Zoology, 1907-39. Social Studies of Science, 19(3), 387-420.

Stephan, S. H., Weist, M., Kataoka, S., Adelsheim, S., \& Mills, C. (2007). Transformation of children's mental health services: The role of school mental health. Psychiatric Services, 58(10), 1330-1338. doi:10.1176/appi.ps.58.10.1330

Suchman, L. (1994). Working relations of technology production and use. Computer Supported Cooperative Work, 2(1), 21-39. doi:10.1007/BF00749282

Tjora, A. (2012). Kvalitative forskningsmetoder i praksis [Qualitative research methods in practice]. Oslo: Gyldendal Norsk Forlag AS.

Vike, H. (2013). Egalitarianisme og byråkratisk individualisme [Egalitarianism and bureaucratic individualism]. Norsk Antropologisk Tidsskrift, 24(3/4), 181-193.

Wenger, E. (2000). Communities of practice and social learning systems. Organization, 7(2), 225-246.

\section{About the Authors}

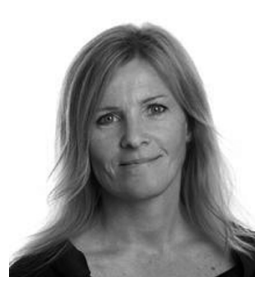

Cecilie Anvik (Dr. Polit. in Social Anthropology) is Associate Professor at Faculty of Social Science Nord University, Norway. Her primary research interests include collaboration and innovation within welfare services, youth in vulnerable transitions, and education, labor market and health. Anvik has contributed to several research publications over the years, the latest article being published in Nordic Welfare Research.

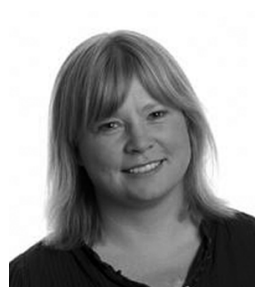

Ragnhild Holmen Waldahl (Can. Polit.) is Research Director at Nordland Research Institute. Her primary research interests include collaboration within and organization of welfare services, welfare policy, organization of innovation, innovation processes, and the intersection of public and non-public actors. Waldahl's latest article has been published in Nordic Welfare Research. 